\title{
Effects of Drought on Net Primary Productivity: Roles of Temperature, Drought Intensity, and Duration
}

\author{
SUN Binfeng ${ }^{1}$, ZHAO Hong ${ }^{1}$, WANG Xiaoke ${ }^{2,3}$ \\ (1. Jinan Environmental Research Institute, Jinan 250100, China; 2. State Key Laboratory of Urban and Regional Ecology, Research \\ Center for Eco-Environmental Sciences, Chinese Academy of Sciences, Beijing 100085, China; 3. Joint Center for Global Change Stud- \\ ies (JCGCS), Beijing 100875, China)
}

\begin{abstract}
Northeast China has experienced frequent droughts over the past fifteen years. However, the effects of droughts on net primary productivity (NPP) in Northeast China remain unclear. In this paper, the droughts that occurred in Northeast China between 1999 and 2013 were identified using the Standardized Precipitation Evapotranspiration Index (SPEI). The NPP standardized anomaly index (NPP-SAI) was used to evaluate NPP anomalies. The years of 1999, 2000, 2001, and 2007 were further investigated in order to explore the influence of droughts on NPP at different time scales (3, 6, and 12 months). Based on the NPP-SAI of normal areas, we found droughts overall decreased NPP by $112.06 \mathrm{Tg}$ C between 1999 and 2013. Lower temperatures at the beginning of the growing season could cause declines in NPP by shortening the length of the growing season. Mild drought or short-term drought with higher temperatures might increase NPP, and weak intensity droughts intensified the lag effects of droughts on NPP.
\end{abstract}

Keywords: drought; net primary productivity (NPP); Standardized Precipitation Evapotranspiration Index (SPEI); NPP Standardized anomaly index (NPP-SAI)

Citation: Sun Binfeng, Zhao Hong, Wang Xiaoke, 2016. Effects of drought on net primary productivity: roles of temperature, drought intensity, and duration. Chinese Geographical Science, 26(2): 270-282. doi: 10.1007/s11769-016-0804-3

\section{Introduction}

Net primary productivity (NPP) is a measure of the net amount of carbon taken up from the atmosphere via photosynthesis and plays a critical role in the global carbon balance. Climate change and climate-related extreme events (e.g., droughts) are anticipated to have a range of crucial consequences, including markedly impact on global carbon balance (Ji and Peters, 2003; Ciais et al., 2005). Extreme climate events have amplified in both frequency and magnitude, and more frequent and severe extreme events will occur during the remainder of the twenty-first century (Parry et al., 2007). Drought is a complex natural disaster that has not yet been identified precisely and universally (Wilhite, 2000). The main cause of drought is below-normal precipitation, and/or above-normal temperature and higher evapotranspiration. Many previous studies have reported the significant impacts of temperature and evapotranspiration on drought conditions (Jeong et al., 2014; Zhang et al., 2014). Severe drought can disturb the photosynthetic function of plants and even destroy vulnerable individuals. It potentially and significantly affects global carbon balance through declining crop yields, delaying in agricultural planting schedules, and increasing forest losses, insect infestation, and diseases (Pantuwan et al., 2002; Parry et al., 2007).

Numbers of recent findings showed that some largescale droughts reduced terrestrial NPP. Zhao and Running (2010) proved that droughts in the Southern

Received date: 2015-07-08; accepted date: 2015-10-16

Foundation item: Under the auspices of Special Issue of National Remote Sensing Survey and Assessment of Eco-Environment Change Between 2000 and 2010 (No. STSN-09-03)

Corresponding author: WANG Xiaoke. E-mail: wangxk@rcees.ac.cn

(C) Science Press, Northeast Institute of Geography and Agroecology, CAS and Springer-Verlag Berlin Heidelberg 2016 
Hemisphere caused a reduction of 0.55 petagrams of carbon in global terrestrial NPP. The Palmer drought severity index (PDSI) and the Terrestrial Ecosystem Model (TEM) have been used to examine the effects of droughts on terrestrial carbon dynamics (Zhang et al., 2014). A strong correlation between drought and NPP anomalies was found in China between 2000 and 2010 (Pei et al., 2013). At continental or national scales, there were also considerably studies reported the drought induced reductions in vegetation productivity (Gilgen and Buchmann, 2009; Zhang et al., 2010; Mohammat et al., 2012; Zhou et al., 2013).

A significant greening trend was reported in middle and high latitude areas during the 1980s and 1990s as a result of climate change and rising atmospheric $\mathrm{CO}_{2}$ concentration (Zhou et al., 2001; Lucht et al., 2002; Piao et al., 2006). It is projected that the increasing trend in vegetation productivity could last until 2050 (Cramer et al., 2001). However, stalled or decreasing trends for the Normalized Difference Vegetation Index (NDVI) have been reported over the last decade (Angert et al., 2005; Park and Sohn, 2010; Piao et al., 2011; Mohammat et al., 2012). These contradicted results require to closely examine the effects of recent droughts on vegetation greening and productivity.

The Northeast China is a key region for food and timber production (Wang, 2001; Li et al., 2006), and plays a crucial role in the global carbon budget (Bousquet et al., 1999). This region is sensitive to climate change according to global climate models (Ye, 1994). Significant warming has occurred in Northeast China, and coincided with a decline in precipitation (Liang et al., 2011). Recently, droughts have occurred more frequently in Northeast China, and their impacts are being aggravated by the rising demand for water. So, investigating the impact of drought on NPP in Northeast China will be favour in steady crop production and ecological security of all over China.

To our knowledge, few attempts were performed to quantify the effects of droughts on NPP using the Standardized Precipitation Evapotranspiration Index (SPEI) in Northeast China. It is indispensable to further investigate the precipitation and temperature changes and explore the effects of droughts on NPP in this cold, semi-arid, and semi-humid region. Herein, the objectives of this study were 1) to estimate the duced decrease in NPP over Northeast China, and 2) to assess the impacts of drought intensity and duration on NPP in Northeast China.

\section{Materials and Methods}

\subsection{Study area}

Northeast China $\left(38^{\circ} 40^{\prime}-53^{\circ} 34^{\prime} \mathrm{N}, 115^{\circ} 05^{\prime}-135^{\circ} 02^{\prime} \mathrm{E}\right)$ covers Heilongjiang, Jilin, and Liaoning provinces, as well as the eastern part of the Inner Mongolia Autonomous Region. It is a geographical region of China that is surrounded by medium-high and low mountains along three sides, including the Changbai Mountains in the southeast, the Da Hinggan Mountains in the northwest, and the Xiao Hinggan Mountains in Northeast (Fig. 1). A large part of this area is characterized by a temperate monsoon continental climate, except for the areas located at $>50^{\circ} \mathrm{N}$, which are dominated by the cold monsoon. Annual mean air temperature varies spatially from $-4.7^{\circ} \mathrm{C}$ to $10.7^{\circ} \mathrm{C}$.

This area is an important timber and crop production zones in China. The predominant land use types are forest, cropland, and grassland. The major types of vegetation are broadleaved deciduous forest, mixed broadleaved deciduous and evergreen coniferous forests, and deciduous coniferous forests from south to north.

\subsection{Data sources}

\subsubsection{Normalized Difference Vegetation Index}

The ten-day synthesis product (S10) with a spatial resolution of $1 \mathrm{~km}$ was used in this study to create a monthly Normalized Difference Vegetation Index (NDVI) dataset by Model View Controller (MVC). This NDVI data set for the period 1999 to 2013 were derived from the Vlaamse Instelling voor Technologisch Onderzock (VITO) Image Processing center (http://www.wgt.vito.be). The temporal resolution of the SPOT VGT NDVI is about 10 days, which makes 36 composites in a one-year cycle. The SPOT NDVI dataset has been corrected to remove the effects of satellite shift and sensor degradation. The simplified method for atmospheric corrections (SMAC) (Rahman and Dedieu, 1994) was used to correct atmospheric contamination due to ozone, aerosols, and water vapour.

\subsubsection{Meteorological data}

The meteorological data including monthly average temperature, monthly total precipitation and monthly 


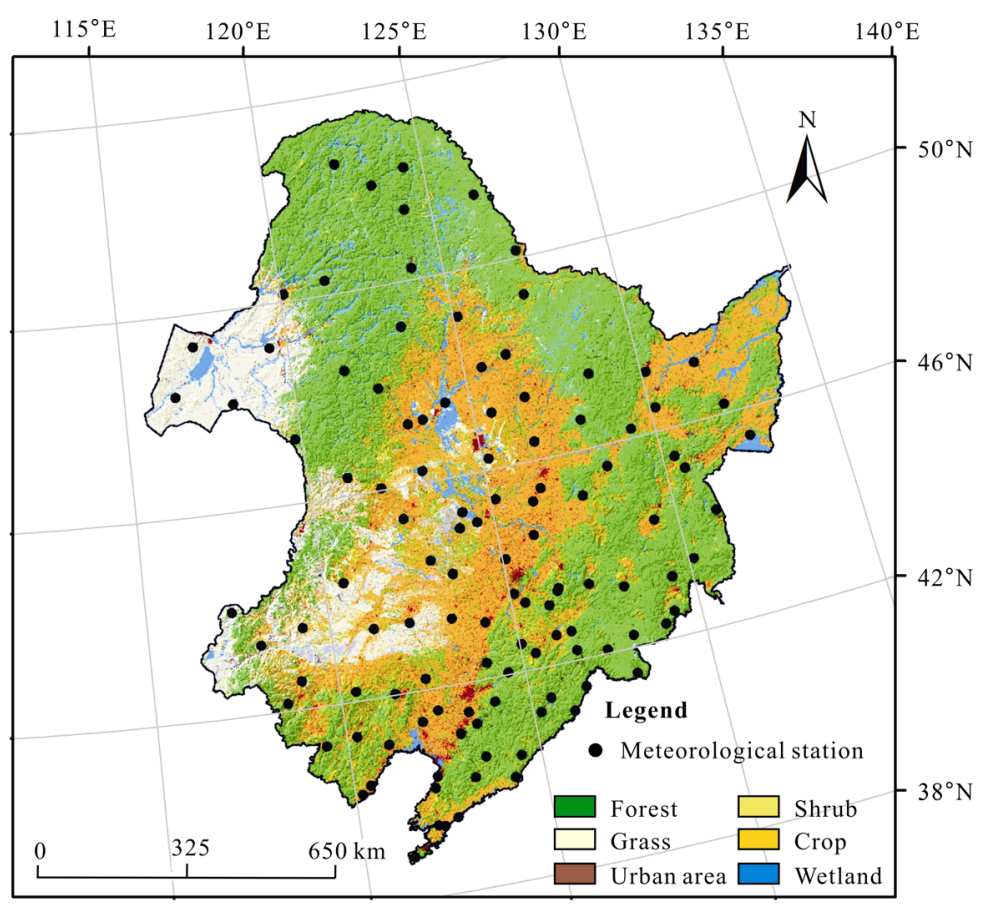

Fig. 1 Meteorological stations and land cover in Northeast China

total solar radiation from 1999 to 2013 were obtained from the China Meteorological Data Sharing Service System (http://cdc.cma.gov.cn/). These meteorological data were interpolated at a $1 \mathrm{~km}$ resolution with the thin-plate smoothing spline method provided by the ANUSPLIN 4.2 programme, which could provide accurate estimates of the spatial climatic variables that reflected the elevation effect (Hutchinson, 1991).

\subsection{Net primary productivity calculation}

\subsubsection{Carnegie-Ames-Stanford Approach}

The Carnegie-Ames-Stanford Approach (CASA) model was used to compute the monthly NPP. The CASA model was employed because it is possible to estimate the NPP based on satellite data and ground data at a large-scale, and it can accurately describe spatial and temporal patterns for NPP (Potter et al., 1993; Imhoff et al., 2004; Yu et al., 2009).

The CASA model calculates NPP fixed by vegetation at a grid cell $x$ in month $t$ as a function of the driving energy for photosynthesis, the absorbed photosynthetically active solar radiation (APAR), and average light utilization efficiency $(\varepsilon)$ (Equation 1).

$$
N P P(x, t)=A P A R(x, t) \times \varepsilon(x, t)
$$

$\operatorname{FPAR}(x, t)$ is the fraction of PAR absorbed by the vegetation canopy, and can be determined from the NDVI.
$\operatorname{SOL}(x, t)$ is the total solar radiation $\left(\mathrm{MJ} / \mathrm{m}^{2}\right)$ of pixel $x$ in time $t$, and 0.5 stands for the fraction of total solar radiation that can be used by vegetation (Equation 2).

$$
\operatorname{APAR}(x, t)=\operatorname{SOL}(x, t) \times \operatorname{FPAR}(x, t) \times 0.5
$$

$\varepsilon(x, t)$ can be expressed by the following equation:

$$
\varepsilon(x, t)=T_{\varepsilon 1}(x, t) \times T_{\varepsilon 2}(x, t) \times W_{\varepsilon}(x, t) \times \varepsilon_{\max }
$$

where $T_{\varepsilon 1}(x, t)$ and $T_{\varepsilon 2}(x, t)$ are temperature stress coefficients, which reflect the reduction in light-use efficiency caused by the temperature factor. $W_{\varepsilon}(x, t)$ is the moisture stress coefficient, which indicates the reduction in light-use efficiency caused by the moisture factor, and $\varepsilon_{\max }$ is the maximum light-use efficiency under ideal conditions. The details of the CASA model can be found in Potter et al. (1993).

\subsubsection{NPP-SAI and NPP anomalies}

The NPP standardized anomaly index was developed by Pei et al. (2013) to identify NPP anomalies. The NPP-SAI (NPP Standardized anomaly index) is defined as:

$$
S A I_{N P P}=\frac{N P P(i)-\overline{N P P}}{\sigma_{N P P}}
$$

where $S A I_{N P P}$ is the NPP anomalies; $N P P(i)$ is the amount of NPP in the year $i$; $\overline{N P P}$ is the mean NPP 
value; and $\sigma_{N P P}$ is the standard deviation for the NPP.

\subsection{Standardized Precipitation Evapotranspira- tion Index as an indicator of droughts}

The Standardized Precipitation Evapotranspiration Index (SPEI) is based on a monthly climatic water balance, which is adjusted using a three-parameter loglogistic distribution to take into account common negative values. The main advantage of the SPEI is its ability to identify evapotranspiration and temperature variability effects on droughts caused by global warming. The method for computing the SPEI has been described in Vicente-Serrano et al. (2010).

The main steps for calculating SPEI are based on the following:

(1) Monthly PET series are estimated by the Hamon method (Hamon, 1961), which is one of the simplest temperature-based PET estimation methods.

(2) The difference between precipitation $(P)$ and PET at different time scales is aggregated.

$D_{n}^{k}=\sum_{i=0}^{k-1}\left(P_{n-1}-P E T_{n-\mathrm{i}}\right)$

where $k$ (months) is the scale of interest; $n$ is the calculation month; $D_{n}^{k}$ is the accumulated difference between the precipitation and PET.

(3) Then the water balance is normalised into a log-logistic probability distribution to calculate the SPEI index series.

The log-logistic distribution was selected for standardizing the $D$ series to calculate the SPEI. The probability density function of a three parameter log-logistic distributed variable is expressed as:

$$
f(x)=\frac{\beta}{\alpha}\left(\frac{x-\gamma}{\alpha}\right)^{\beta-1}\left(1+\left(\frac{x-\gamma}{\alpha}\right)^{\beta}\right)^{-2}
$$

where $\alpha, \beta$, and $\gamma$ are the scale, shape, and origin parameters, respectively.

$$
\begin{aligned}
& \alpha=\frac{\left(w_{0}-2 w_{1}\right) \beta}{\Gamma(1+1 / \beta) \Gamma(1-1 / \beta)} \\
& \beta=\frac{2 w_{1}-w_{0}}{6 w_{1}-w_{0}-6 w_{2}} \\
& \gamma=w_{0}-\alpha \Gamma(1+1 / \beta) \Gamma(1-1 / \beta)
\end{aligned}
$$

The probability distribution function of the $D$ series is given by:

$$
F(x)=\left[1+\left(\frac{\alpha}{x-\gamma}\right)^{\beta}\right]^{-1}
$$

With $F(x)$ the SPEI can easily be obtained as the standardized values of $F(x)$.

For $P \leq 0.5, S P E I=W-\frac{C_{0}+C_{1} W+C_{2} W^{2}}{1+d_{1} W+d_{2} W^{2}+d_{3} W^{3}}$

where $w=\sqrt{-2 \ln (P)}, P$ is the probability of $D$ value, $P$ $=1-F(x)$.

For $P>0.5, \quad S P E I=\frac{C_{0}+C_{1} W+C_{2} W^{2}}{1+d_{1} W+d_{2} W^{2}+d_{3} W^{3}}-W$

where $w=\sqrt{-2 \ln (1-P)}, P=1-F(x)$. The constants are: $C_{0}=2.515517, C_{1}=0.802853, C_{2}=0.010328, d_{1}=$ $1.432788, d_{2}=0.189269, d_{3}=0.001308$.

\subsection{Impacts of droughts on NPP}

\subsubsection{Identity of drought-affected areas}

Monthly SPEI data were calculated over 3 month, 6 month, and 12 month time scales based on 50 year precipitation and temperature data (1963-2013) across Northeast China. Then the mean SPEI of the growing season (May to September) was used to classify the drought and wetness condition of our study area (Table 1). Only drought affected areas were used to assess the impacts of droughts on NPP. In this paper, the droughtaffected areas are areas with a SPEI of less than -0.5 .

\subsubsection{Evaluation impacts of droughts on NPP}

The monthly NPP across Northeast China was modelled by the CASA model. Annual NPP was obtained through the summation of the monthly values. The NPP anomalies were calculated using Equation (4) based on the

Table 1 Classification of dryness/wetness based on Standardized Precipitation Index (SPI)

\begin{tabular}{lc}
\hline Classification & SPI \\
\hline Extreme drought & $\leq-2.0$ \\
Severe drought & $-2.0--1.5$ \\
Moderate drought & $-1.5--1.0$ \\
Mild drought & $-1.0--0.5$ \\
Near normal & $-0.5-0.5$ \\
Mild wet & $0.5-1.0$ \\
Moderate wet & $1.0-1.5$ \\
Severe wet & $1.5-2.0$ \\
Extreme wet & $\geq 2.0$ \\
\hline
\end{tabular}


annual NPP from 1999 to 2013. The NPP-SAI for various ecosystems was used to calculate Pearson correlation coefficients for SPEI at the three time scales $(3,6$, and 12 months) with a spatial resolution of $1 \mathrm{~km}$.

In order to estimate the decrease in NPP, we compared the NPP-SAI in drought areas with that in normal areas. This study estimated drought-induced decline in NPP for forest, cropland, and grasslands. The selection of normal areas has to meet the following two criterions: adjacent to the drought areas, and the same land use type.

The relationship between temperature and NPP change was further investigated using 1000 randomly sampled points. $\Delta T$ and $\Delta$ NPP were estimated to explore the effect of temperature on NPP. $\Delta T$ is the difference between the monthly temperature in May, 1999 and the temperature mean in May, 1999-2013 over Northeast China. $\triangle$ NPP is the difference between the NPP in May, 1999 and the NPP mean in May, 1999-2013.

\section{Results and Discussion}

\subsection{NPP validation}

We selected the plot sites with the same vegetation types as those on the vegetation map used by $\mathrm{Ni}$ et al. (2001). Figure 2 records the relationship between the observed NPP and simulated NPP $\left(R^{2}=0.74, P<0.01\right)$ and indicates that the model's estimation accuracy is satisfactory.

\subsection{SPEI-based drought assessment}

Over the past fifteen years (1999-2013), Northeast

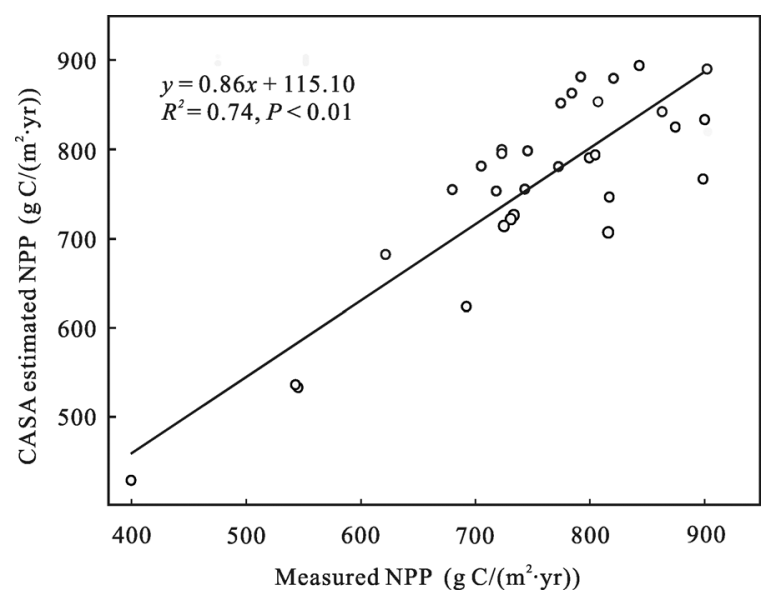

Fig. 2 Validation of CASA model in Northeast China through analyzing correlation between simulated NPP $\left(\mathrm{g} \mathrm{C} /\left(\mathrm{m}^{2} \cdot \mathrm{yr}\right)\right)$ based on CASA model and field-observed NPP
China has witnessed several drought events. Figure 3 gives the evolution of SPEI over 3, 6, and 12 months intervals between 1999 and 2013. The dry or wet months can be identified from the SPEI values, which considerably deviate from the median over the study period. At the 3-month scale, SPEI showed a higher temporal frequency of dry and wet periods. At the 12-month scale, SPEI, drought, and wet periods manifested a lower temporal frequency and a longer duration. Two dry periods between 1999 and 2013 (1999-2002 and 2007-2008) were identified using the SPEI (Fig. 3).

Figure 4 records the spatial distribution of drought severity in Northeast China from 1999 to 2013 at the 6-month scale. More than half of the area experienced drought episodes in 1999, 2000, 2001, and 2007. In 1999 , the drought-affected areas reached $6.70 \times 10^{5} \mathrm{~km}^{2}$, covering $54.26 \%$ of the entire study area. The severe/extreme drought, moderate drought, and mild drought areas reached $2720 \mathrm{~km}^{2}, 2.93 \times 10^{5} \mathrm{~km}^{2}$, and $3.75 \times 10^{5} \mathrm{~km}^{2}$, respectively. In 2000 , the areas affected by drought increased to $9.47 \times 10^{5} \mathrm{~km}^{2}$ (approximately $76.63 \%$ of the total area). The severe/extreme drought areas expanded to $1.04 \times 10^{5} \mathrm{~km}^{2}$, and the moderate drought areas were $5.47 \times 10^{5} \mathrm{~km}^{2}$. In 2001 , the drought-affected areas reached $9.77 \times 10^{5} \mathrm{~km}^{2}$, equivalent

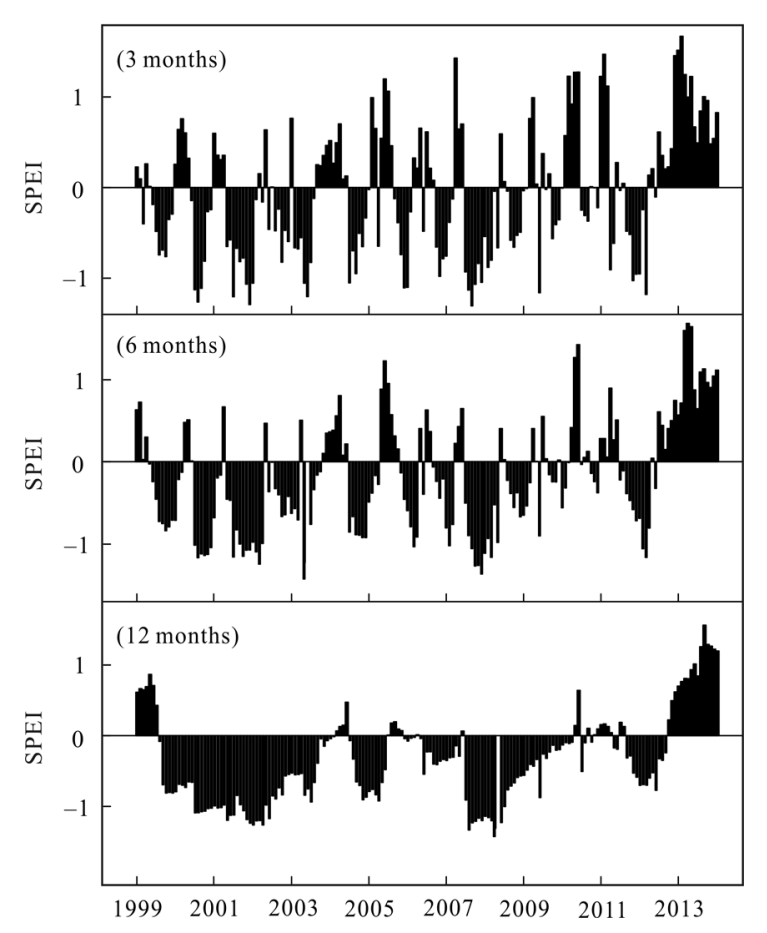

Fig. 3 Data series of SPEI at times scales of 3, 6 and 12 months for period 1998-2013 of Northeast China 
to $79.08 \%$ of the entire area. The severe/extreme drought areas expanded to $2.10 \times 10^{5} \mathrm{~km}^{2}$. In 2007 , $64.13 \%$ of the study area was affected by drought and the mild drought areas covered $5.35 \times 10^{5} \mathrm{~km}^{2}$ (approximately $67.56 \%$ of the drought-affected areas). In general, our results indicate that Northeast China has been affected by frequent droughts over the past fifteen years, which is in consistence with the study of Liu et al. (2014).

\subsection{Impact of droughts on NPP}

\subsubsection{Drought impacts on annual NPP}

Between 1999 and 2013, the NPP was higher in wetter years than in drier years (Fig. 5). The annual NPP and SPEI are significantly positively correlated based on the Pearson correlation analysis $(r=0.67, P<0.01)$, and the Pearson correlation coefficient of the annual NPP and the drought-affected areas was -0.55 , which may suggest that drought reduced the NPP in our study area. And this meant that droughts also had an important ef- fect on the NPP, and this was confirmed by Zhao and Running (2010) and Pei et al. (2013).

The droughts in 1999, 2000, 2001, and 2007 were further investigated by Pearson correlation analysis in order to examine the effects of droughts on NPP. The correlation coefficients between mean SPEI in the growing season and NPP-SAI values were calculated at the three time scales for these four years. The droughts in 1999 had significant effects on the NPP. The correlation of SPEI and NPP-SAI was significantly positive (Table 2). The correlation coefficient was largest (0.52) for forests at the 12 month time scale. While, for cropland and grassland, the correlation coefficients were highest at the 6 month time scale. This was also the case for 2000 (Table 2). In 2001, the correlation coefficients were highest at the 12 month time scale for all the ecosystems. During these successive three years, the Pearson coefficients for forest continued to drop, but in 2001, the coefficient for grassland reached its peak value. During this period, the Pearson coefficient for

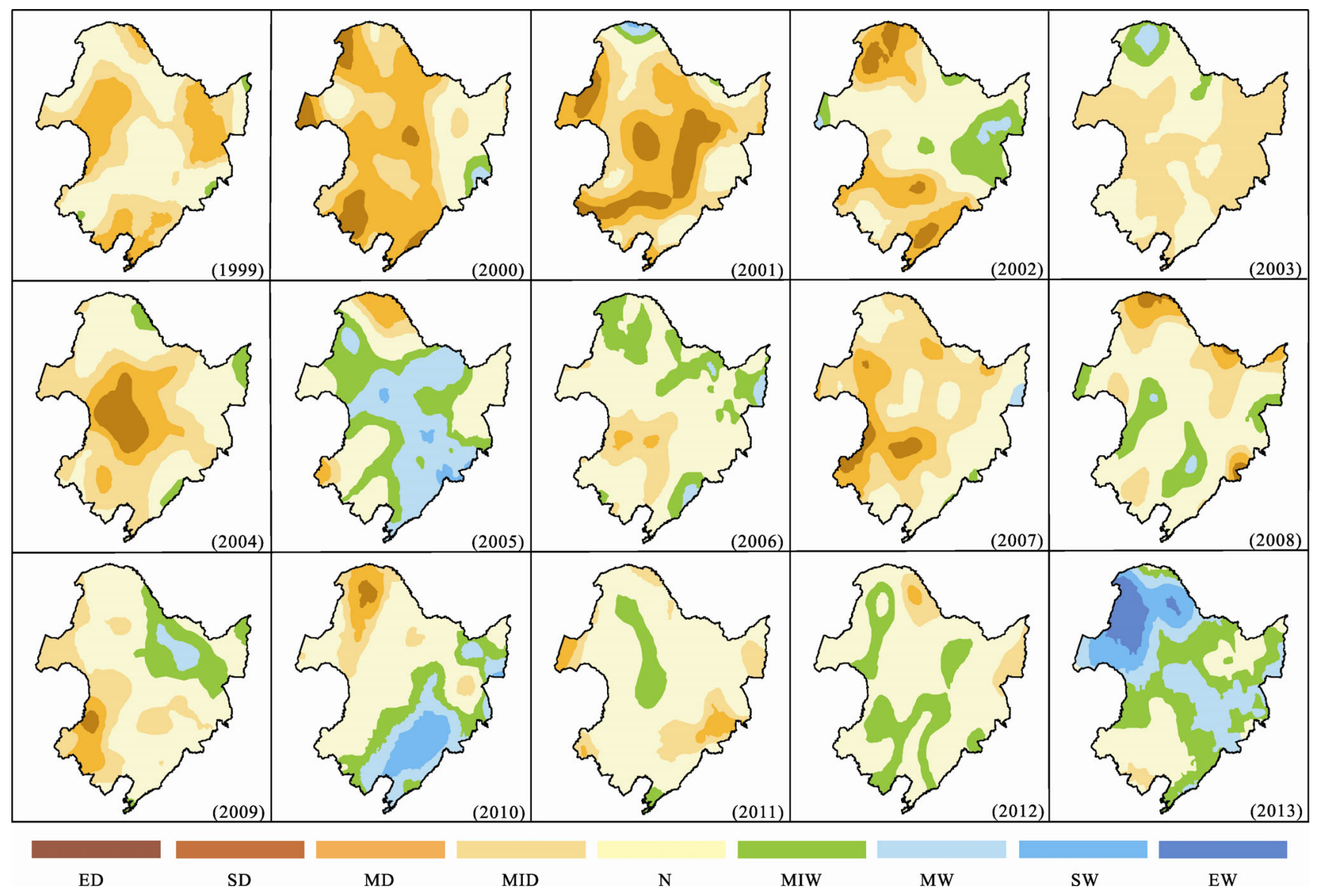

Fig. 4 Spatial distribution of drought severity in Northeast China during 1999-2013. ED, extreme drought; SD, severe drought; MD, moderate drought; MID, mild drought; N, near normal; MIW, mild wet; MW, moderate wet; SW, severe wet; EW, extreme wet 


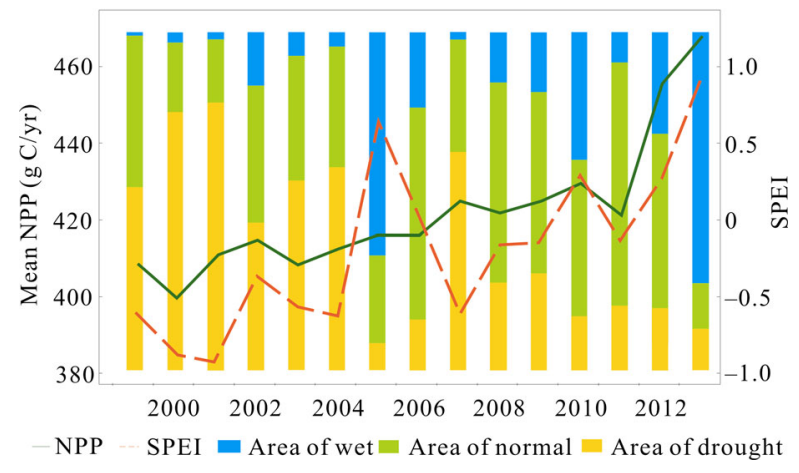

Fig. 5 Interannual variations of NPP, SPEI and drought areas in Northeast China during 1999-2013

cropland was smaller than for forest and grassland. In
2007, the Pearson correlation coefficients attained their maximums at the 6 month time scale for forest and cropland, whereas, the Pearson correlation coefficients peaked at the 3 month time scale for grassland.

In this study, a comparison of NPP variation between drought areas with adjacent normal areas was carried out over the past 15 years. Droughts reduced 112.06 Tg C in NPP during the periods from 1999 to 2013 (Fig. 6). The largest reduction in NPP was observed in 2000 , with a decrease of $29.08 \mathrm{Tg}$ C. A slight increase of 4.45 Tg C in NPP caused by droughts was recorded in 2012. Between 1999 and 2013, the decrease in NPP for forest was the greatest $(46.32 \mathrm{Tg} \mathrm{C})$, followed by cropland (34.72 $\mathrm{Tg} \mathrm{C})$ and grassland (31.04 Tg C).

Table 2 Pearson correlation coefficients $R$ at different time scales in 1999, 2000, 2001 and $2007(P<0.001)$

\begin{tabular}{|c|c|c|c|c|c|c|c|}
\hline \multirow{2}{*}{ Year } & \multirow{2}{*}{ Ecosystem } & \multicolumn{2}{|c|}{3 months } & \multicolumn{2}{|c|}{6 months } & \multicolumn{2}{|c|}{12 months } \\
\hline & & $R$ & SPEI & $R$ & SPEI & $R$ & SPEI \\
\hline \multirow{3}{*}{1999} & Forest & 0.38 & -0.95 & 0.33 & -1.03 & 0.52 & -0.91 \\
\hline & Cropland & 0.34 & -0.84 & 0.37 & -0.90 & 0.23 & -0.82 \\
\hline & Grassland & 0.47 & -0.84 & 0.47 & -0.85 & 0.44 & -0.90 \\
\hline \multirow{3}{*}{2000} & Forest & 0.44 & -1.07 & 0.44 & -1.10 & 0.48 & -1.10 \\
\hline & Cropland & 0.41 & -1.14 & 0.46 & -1.15 & 0.43 & -1.26 \\
\hline & Grassland & 0.44 & -1.12 & 0.46 & -1.20 & 0.41 & -1.13 \\
\hline \multirow{3}{*}{2001} & Forest & 0.20 & -0.93 & 0.24 & -0.99 & 0.37 & -1.13 \\
\hline & Cropland & 0.28 & -1.11 & 0.27 & -1.23 & 0.39 & -1.29 \\
\hline & Grassland & 0.63 & -1.14 & 0.57 & -1.23 & 0.69 & -1.28 \\
\hline \multirow{3}{*}{2007} & Forest & 0.58 & -0.87 & 0.64 & -0.87 & 0.53 & -1.02 \\
\hline & Cropland & 0.53 & -0.87 & 0.55 & -0.88 & 0.53 & -1.04 \\
\hline & Grassland & 0.41 & -1.04 & 0.35 & -1.08 & 0.37 & -1.22 \\
\hline
\end{tabular}

Note: $R$ represents Pearson correlation coefficient between average SPEI in grow season and annual NPP-SAI

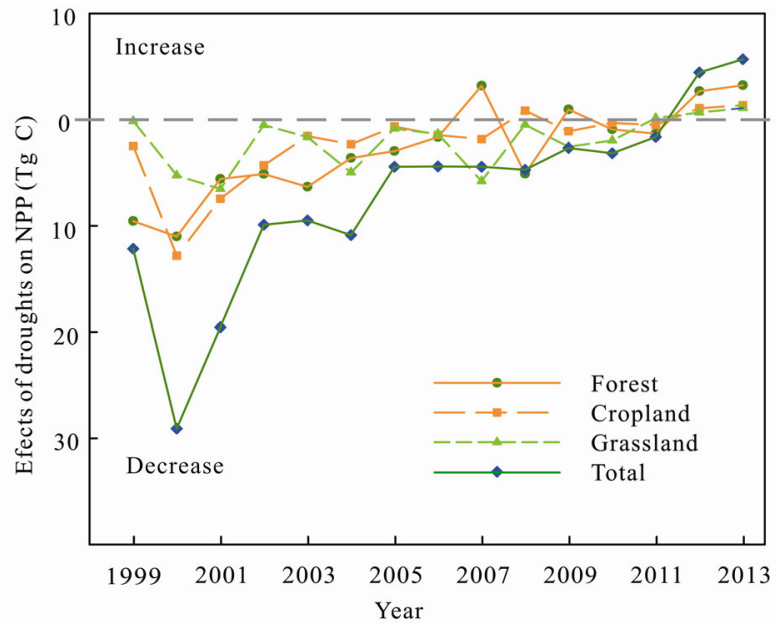

Fig. 6 Effects of droughts on NPP in Northeast China during 1999 and 2013

\subsubsection{Drought impacts on monthly NPP}

Monthly NPP data of the growing seasons in the severe drought years $(1999,2000,2001$, and 2007) was used to investigate the impacts of drought. Figure 7 illustrated the variation in monthly NPP (along with precipitation and temperature). In 1999, 2000, 2001, and 2007, the precipitation of growing season was respectively lower $14.13 \%, 13.78 \%, 16.75 \%$, and $17.49 \%$ than the averaged 15 years. Simultaneously the higher temperature in 1999, 2000, and 2007 in the growing season exacerbated the water shortages. The meteorological differences among these years may contribute to the differences in monthly NPP reduction. The NPP reduction in 1999, 2000, and 2001 occurred primarily in June and July. In 1999 , the largest decrease in monthly NPP was $25.26 \%$ 
in May. The temperature in this month was $1.33^{\circ} \mathrm{C}$ lower than the 15 years' mean value. Figure 8 shows that $\Delta T$ was significantly positively related to $\triangle \mathrm{NPP}(P$ $<0.0001)$ with a $R^{2}$ of 0.41 . It indicated that a lower temperature at the beginning of a dry growing season would shorten the length of the growing season and lead to a decline in net carbon uptake (Noormets et al., 2008). In 2007, NPP increased in July due to the higher temperatures (Pei et al., 2013).

Figure 9 gives the variation in monthly NPP by ecosystems in 2000 and 2007. The reduction of monthly NPP in 2000 lasted from July to August for all ecosystem types, with a decrease of $29.08 \mathrm{Tg}$ C. For the forest, the largest reduction of monthly NPP happened in August $\left(13.44 \mathrm{~g} \mathrm{C} /\left(\mathrm{m}^{2} \cdot \mathrm{month}\right)\right)$, whereas occurrence in July for cropland and grassland (12.52 and $21.54 \mathrm{~g} \mathrm{C} /\left(\mathrm{m}^{2} \cdot \mathrm{month}\right)$, respectively). In 2007 , drought caused an increase of $3.19 \mathrm{Tg} \mathrm{C}$ in forest NPP. The largest increase in the monthly NPP was recorded for forest in July $\left(10.58 \mathrm{~g} \mathrm{C} /\left(\mathrm{m}^{2} \cdot \mathrm{month}\right)\right)$. In contrast, grassland experienced a sustained decrease from May to September in 2007. Our results implied that grassland was more sensitive to droughts than forest and cropland in Northeast China.

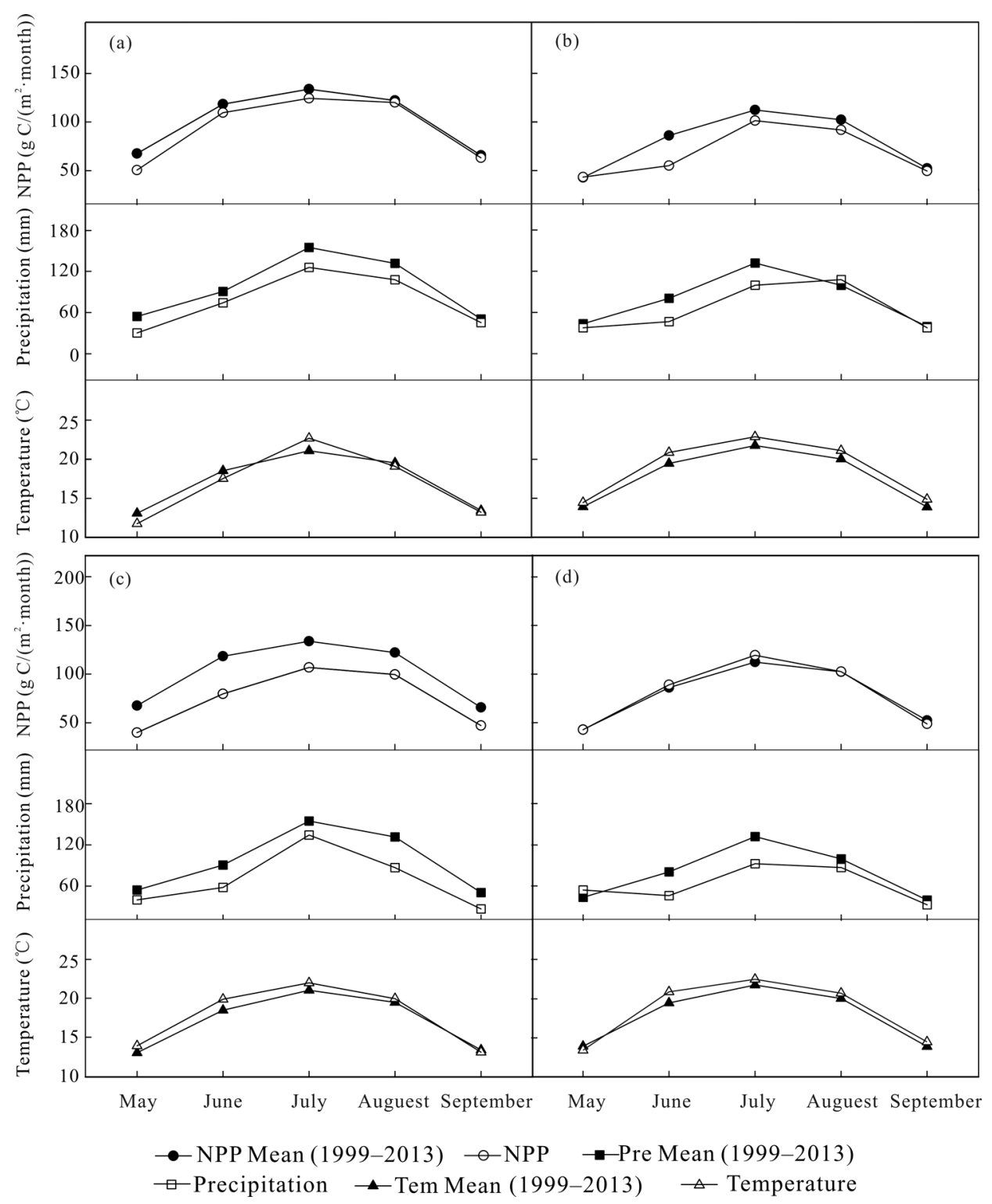

Fig. 7 Monthly NPP, temperature, and precipitation averaged over Northeast China in growing seasons (May to September) of (a) 1999, (b) 2000, (c) 2001 and (d) 2007 


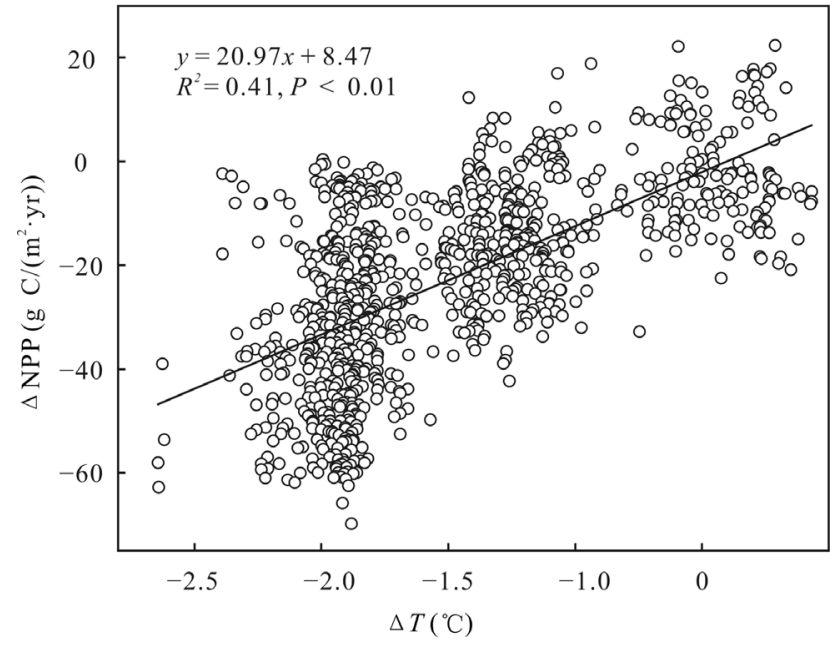

Fig. 8 Relationship between $\triangle N P P$ and $\Delta T$. $\triangle N P P$ is difference between NPP in May in 1999 and NPP Mean in May (1999-2013), $\Delta T$ is difference between monthly temperature in May in 1999 and temperature Mean in May (1999-2013) over Northeast China

\subsubsection{Impacts of drought intensity and duration on NPP}

Over the past fifteen years, the annual NPP values were significantly positively correlated with SPEI, and significantly negatively correlated with the drought- affected areas. However, the effects of drought on annual NPP and monthly NPP were variable (Fig. 6 and Fig. 9). Whether drought decreased or increased NPP was associated with its intensity, duration, and the cumulative and lag effects of vegetation responses to droughts ( $\mathrm{Ji}$ and Peters, 2003; Pei et al., 2013).

In order to estimate the influence of drought intensity on NPP, the mean NPP-SAI for different drought categories in 1999, 2000, 2001, and 2007 were calculated (Fig. 10). During these four years, the mean value of NPP-SAI decreased with the level of drought severity. In 2001, the mean NPP-SAI of the extreme droughtareas was less than -0.4 , which meant the NPP would sharply decrease under extreme drought conditions. However, in 2007, in forest and cropland, the mean NPP-SAI value of the mild droughts-affected areas was positive, whereas negative for grassland. For forest and cropland, the mean temperatures of the mild droughtaffected areas were higher than that in the normal areas, but the opposite occurred in grassland, indi cating that

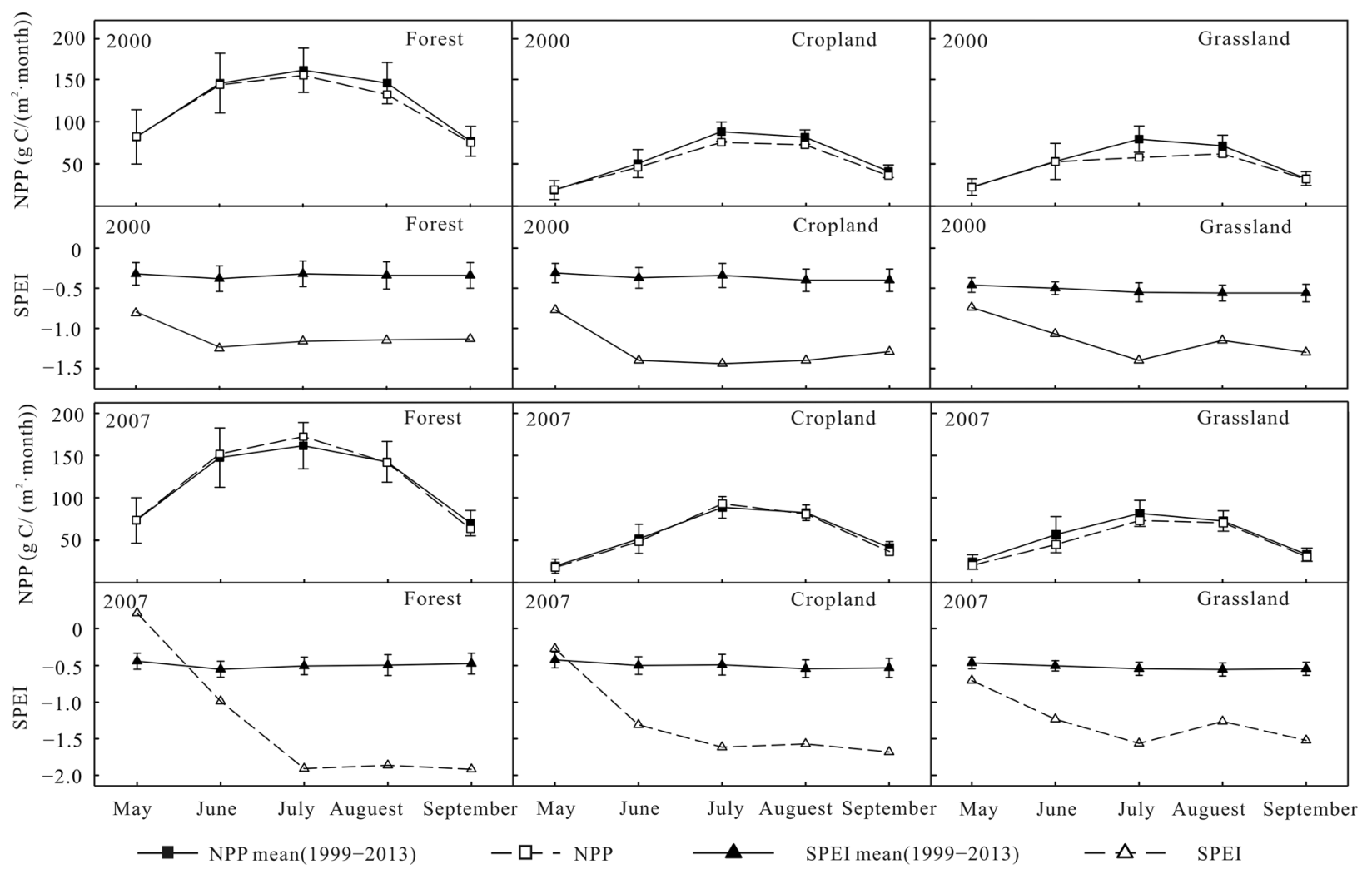

Fig. 9 Monthly variations in mean NPP and SPEI in growing season (May to September) of 2000 and 2007, and the 1999-2013 average in Northeast China. The dashed and solid lines denote the 15 years' mean and monthly NPP, respectively. The error bars denote mean \pm standard error 
higher temperatures in mild drought-affected areas resulted in an increment in the NPP (Zhao and Running, 2010; Pei et al., 2013). Alternatively, less cloudiness, caused by droughts, increases the incoming photosynthetically active radiation (Xiao et al., 2009) and this may accelerate the growth of plants.

The NPP variations also depend on the duration of droughts: longer drought durations are always associated with greater NPP-SAI values (Zhang et al., 2014). We defined the duration of droughts as the number of months in a growing season (May to September) when the SPEI fell below -0.5 . Based on this definition, the duration of a drought ranged from 0 to 5 , and the corresponding mean NPP-SAI was calculated to detect the effects of drought duration on NPP (Fig. 10). In our research areas, drought intensity would increase along with the drought duration. In 2001 and 2007, droughts respective with duration of 1 to 2 months and less than 4 months both improved the NPP in forest, cropland, and grassland. This meant that short-term droughts could increase the NPP.

These results indicated that the effect of droughts on the NPP was associated with drought intensity and duration in our study area. Mild droughts combined with higher temperatures could increase the NPP in Northeast
China.

Significant warming has occurred in Northeast China, and coincided with a decline in precipitation (Liang et al., 2011). Droughts have occurred more frequently in the Northeast China, and their impacts are being aggravated by the rising demand for water. To examine the effects of frequency, duration, severity, and the spatial extent of droughts on NPP could be helpful to minimize climate change impacts.

\subsubsection{Lag effect of droughts on NPP}

The lagging effects of vegetation responses to a lack of precipitation prevented a decrease in the NPP (Ji and Peters, 2003). In our study, the NPP in Northeast China most significantly responded to long timescale SPEI values (6 months and 12 months). In the US Great Plains, Ji and Peters (2003) used the SPI (Standardized Precipitation Index) to quantify the effects of droughts on the NDVI and found that the 3 month SPI was most strongly correlated with the NDVI during the midpoint of the growing season, while Lotsch et al. (2003) suggested the 5 month SPI best assessed the response of terrestrial ecosystems to droughts. Liu et al. (2014) also reported that Chinese semiarid and sub-humid ecosystems responded to droughts over long timescales, and this was consistent with our results.

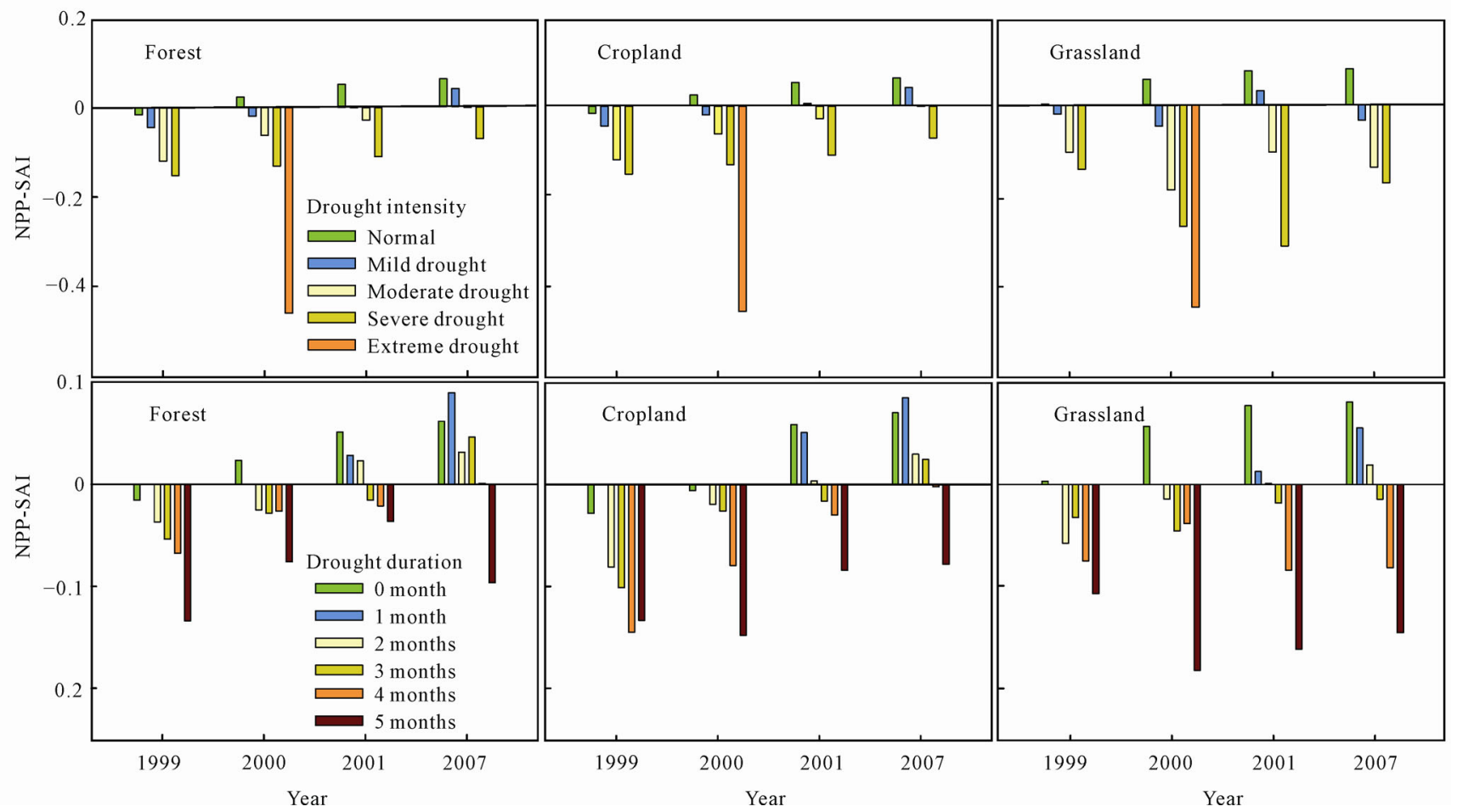

Fig. 10 NPP-SAI of forest, cropland and grassland against intensity of drought in 1999, 2000, 2001 and 2007 
The lag time of drought effects on growth indicators is specific to the vegetation types and local conditions (Liu et al., 2014). Recent studies have shown that in China, the correlation between NPP anomalies and drought intensity was strongest during and after the peak drought intensity period (Pei et al., 2013). The lagging effects of the vegetation were obvious, and a recent study found that droughts exerted an approximate one-month negative lag effect on potential productivity in Qianyanzhou, Jiangxi Province, China (Huang et al., 2013). In our study, the lag effects of droughts on ecosystems were found in 1999, 2000, and 2007. In 1999, for grassland, the drought intensity (SPEI) were the greatest for the 12 month timescale, but the correlations were the highest $(-0.9)$ for the 6 month timescale. The same results were recorded for cropland and forest in 2000 (Fig. 9). For forest and cropland, the decrease in the monthly NPP did not happen instantaneously when drought occurred in May, 2000 (Fig. 9). The same occurred in 2007 for forest, cropland, and grassland. The drought intensity was weaker in 2007 than 1999, 2000, and 2001. So we can deduce that weak intensity drought may intensify the lag effects of drought on the NPP.

\subsection{Uncertainties and implications}

The NPP is affected by a number of factors, such as climate, disturbances, and land cover change. In this study, we investigated the influence of droughts on NPP in Northeast China. However, drought can trigger many ecosystem disturbances (Hanson and Weltzin, 2000; Westerling et al., 2006), such as wildfires, disease, pest attack, increased mortality, or re-growth (Allen et al., 2010; Peng et al., 2011; vander Molen et al., 2011; Ma et al., 2012). Wildfire is a dominant disturbance in Northeast China (Tao et al., 2013; Wu et al., 2014). Most wildfires happened in the Greater Hinggan region in 2003 and 2006, where two large forest fires occurred (Tao, 2013). Fire can directly affect the NPP (Peng and Michael, 1999) and lead to an overestimation of drought effects on NPP. If there is to be a more accurate assessment of the drought effects on NPP, then these indirect effects of droughts should be carefully considered in future research.

\section{Conclusions}

In this study, we investigated the impact of droughts on the NPP in Northeast China between 1999 and 2013, and found that more than half of Northeast China experienced drought episodes in 1999, 2000, 2001, and 2007. The main conclusions included:

(1) Based on the SPEI, droughts occurred extensively and frequently in Northeast China between 1999 and 2013, especially in 1999, 2000, 2001, and 2007. The spatial patterns of the droughts differed in these four years.

(2) Between 1999 and 2013, droughts caused a NPP decrease of $112.06 \mathrm{Tg} \mathrm{C}$ in Northeast China, of which a $26 \%$ decrease occurred in 2000. However, in 2012, droughts caused a slight increase in NPP $(4.45 \mathrm{Tg} \mathrm{C})$.

(3) At the beginning of the growing season, lower temperatures promoted the decrease in NPP by shortening the length of growing season, which led to a decline in net carbon uptake.

(4) Mild drought, combined with higher temperatures, promoted an increase in NPP in Northeast China. Due to the differences in intensity and duration of droughts, some uncertainties were found in the effects of droughts on the NPP.

(5) Weak intensity droughts intensified the lag effect in responses of ecosystems to droughts. The NPP in Northeast China most significantly responded to longer timescale SPEI values (6 and 12 months).

Droughts have occurred more frequently in the Northeast China, and their impacts are being aggravated by the rising demand for water. To examine the effects of frequency, duration, severity, and the spatial extent of droughts on NPP could be beneficial to minimize climate change impacts.

\section{References}

Allen C D, Macalady A K, Chenchouni H et al., 2010. A global overview of drought and heat induced tree mortality reveals emerging climate change risks for forests. Forest Ecology and Management, 259(4): 660-684. doi: 10.1016/j.foreco.2009.09. 001

Angert A, Biraud S, Bonfils C et al., 2005. Drier summers cancel out the $\mathrm{CO}_{2}$ uptake enhancement induced by warmer springs. Proceedings of the National Academy of Sciences of the United States of America, 102(31): 10823-10827. doi: 10. 1073/pnas. 0501647102

Bousquet P, Ciais P, Peylin P et al., 1999. Inverse modeling of annual atmospheric $\mathrm{CO}_{2}$ sources and sinks I. Method and control inversion. Journal of Geophysical Research-atmospheres, 104(D21): 175-193. doi: 10.1029/1999JD900342 
Ciais P, Reichstein M, Viovy N et al., 2005. Europewide reduction in primary productivity caused by the heat and drought in 2003. Nature, 437(7058): 529-533. doi: 10.1038/nature03972

Cramer W, Bondeau A, Woodward, F I et al., 2001. Global response of terrestrial ecosystem structure and function to $\mathrm{CO}_{2}$ and climate change: results from six dynamic global vegetation models. Global Change Biology, 7(4): 357-373. doi: 10. 1046/j.1365-2486.2001.00383.x

Gilgen A K, Buchmann N, 2009. Response of temperate grasslands at different altitudes to simulated summer drought differed but scaled with annual precipitation. Biogeosciences, 6(3): 5217-5250. doi: 10.5194/bg-6-2525-2009

Hamon W R, 1961. Estimating potential evapotranspiration. Journal of Hydraulics Division, Proceedings of the American Society of Civil Engineers, 87(3): 107-120. doi: 10.1061/ JYCEAJ.0000539

Hanson P J, Weltzin J F, 2000. Drought disturbance from climate change: response of United States forests. Science of the Total Environment, 262(3): 205-220. doi: 10.1016/S0048-9697(00) 00523-4

Huang K, Wang S, Zhou L et al., 2013. Effects of drought and ice rain on potential productivity of a subtropical coniferous plantation from 2003 to 2010 based on eddy covariance flux observation. Environmental Research Letters, 8(3): 035021. doi: 10.1088/1748-9326/8/3/035021

Hutchinson M F, 1991. The Application of Thin Plate Smoothing Splines to Continent-wide Data Assimilation. BMRC Research Report No. 27, Data Assimilation Systems, Bureau of Meteorology, Melbourne, 104-113.

Imhoff M L, Bounoua L, DeFries R et al., 2004. The consequences of urban land transformation on net primary productivity in the United States. Remote Sensing and Environment, 89(4): 434-43. doi: 10.1016/j.rse.2003.10.015

Jeong D I, Sushama L, Khaliq M N, 2014. The role of temperature in drought projections over North America. Climatic Change, 127(2): 289-303. doi: 10.1007/s10584-014-1248-3

Ji L, Peters A J, 2003. Assessing vegetation response to drought in the northern Great Plains using vegetation and drought indices. Remote Sensing and Environment, 87(1): 85-98. doi: 10.1016/ S0034-4257(03)00174-3

Li Peng, Wang Yubin, Tan Xiangyong, 2006. Grain production and trade analysis in Northeast China. Journal of China Agricultural University (Social Sciences Edition), 62(1): 57-62. (in Chinese)

Liang L, Li L, Liu Q, 2011. Precipitation variability in Northeast China from 1961 to 2008. Journal of Hydrology, 404(1-2): 67-76. doi: 10.1016/j.jhydrol.2011.04.020

Liu Y, Zhou Y, Ju W et al., 2014. Impacts of droughts on carbon sequestration by China's terrestrial ecosystems from 2000 to 2011. Biogeosciences, 11: 2583-2599. doi: 10.5194/bg-112583-2014

Lotsch A, Fried M A, Anderson B T et al., 2003. Coupled vegetation-precipitation variability observed from satellite and climate records. Geophysical Research Letters, 30(14): 125-132. doi: 10.1029/2003GL017506
Lucht W, Prentice I C, Myneni R B et al., 2002. Climatic control of the highlatitude vegetation greening trend and Pinatubo effect. Science, 296(5573): 1687-1689. doi: 10.1126/science.1071828

Ma Z, Peng C, Zhu Q et al., 2012. Regional drought-induced reduction in the biomass carbon sink of Canada' boreal forests. Proceedings of the National Academy of Sciences of the United States of America, 109(7): 2423-2427. doi: 10.1073/ pnas. 1111576109

Mohammat A X, Wang X, Xu X T et al., 2012. Drought and spring cooling induced recent decrease in vegetation growth in Inner Asia. Agricultural and Forest Meteorology, 178: 21-30. doi: 10.1016/j.agrformet.2012.09.014

Ni J, Zhang X S, Scurlock, J M O, 2001. Synthesis and analysis of biomass and net primary productivity in Chinese forests. Annals of Forest Science, 58(4): 351-384. doi: 10.1051/forest: 2001131

Noormets A, McNulty S G, DeForest J L et al., 2008. Drought during canopy development has lasting effect on annual carbon balance in a deciduous temperate forest. New Phytologist, 179(3): 818-828. doi: 10.1111/j.1469-8137.2008.02501.x

Pantuwan G, Fukai S, Cooper M et al., 2002. Yield Response of Rice (Oryza Sativa L.) Genotypes to different types of drought under rainfed lowlands: part 1. Grain yield and yield components. Field Crops Research, 73(2-3): 153-168. doi: 10.1016/ S0378-4290(01)00187-3

Park H S, Sohn B J, 2010. Recent trends in changes of vegetation over East Asia coupled with temperature and rainfall variations. Journal of Geophysical Research-Atmospheres, 115 (D14): D14101. doi: 10.1029/2009JD012752

Parry M, Canziani OF, Palutikof J et al., 2007. Climate Change 2007: Impacts, Adaptation and Vulnerability: Working Group II Contribution to the Fourth Assessment Report of the IPCC Intergovernmental Panel on Climate Change. Cambridge: Cambridge University Press.

Pei F, Li X, Liu X et al., 2013. Assessing the impacts of droughts on net primary productivity in China. Journal of Environmental Management, 114(15): 362-371. doi: 10.1016/j.jenvman.2012. 10.031

Peng C H, Michael J, 1999. Modelling the response of net primary productivity (NPP) of boreal forest ecosystems to changes in climate and fire disturbance regimes. Ecological Modelling, 122(3): 175-193. doi: 10.1016/S0304-3800(99) 00137-4

Peng C, Ma Z, Lei X et al., 2011. A drought-induced pervasive increase in tree mortality across Canada's boreal forests. $\mathrm{Na}$ ture Climate Change, 1: 467-471. doi: 10.1038/nclimate1293

Piao S, Mohammat A, Fang J et al., 2006. NDVI-based increase in growth of temperate grasslands and its responses to climate changes in China. Global Environmental Change, 16(4): 340348. doi: 10.1016/j.gloenvcha.2006.02.002

Piao S, Wang X, Ciais P et al., 2011. Changes in satellite-derived vegetation growth trend in temperate and boreal Eurasia from 1982 to 2006. Global Change Biology, 17(10): 3228-3239. doi: 10.1111/j.1365-2486.2011.02419.x

Potter C, Randerson J T, Field C B et al., 1993. Terrestrial eco- 
system production: a process model based on global satellite and surface data. Global Biogeochem Cycles, 7(4): 811-841. doi: 10.1029/93GB02725

Rahman H, Dedieu G, 1994. SMAC: a simplified method for the atmospheric correction of satellite measurements in the solar spectrum. International Journal of Remote Sensing, 15(1): 123-143. doi: 0.1080/01431169408954055

Tao J, Zhang Y J, Yuan X Y et al., 2013. Analysis of forest fires in Northeast China from 2003 to 2011. International Journal of Remote Sensing, 34(22): 8235-8251. doi: 10.1080/01431161. 2013.837229

Vander Molen, Dolman M K, Ciais A J et al., 2011. Drought and ecosystem carbon cycling. Agricultural and Forest Meteorology, 151(7): 765-773. doi: 10.1016/j.agrformet.2011.01.018

Vicente-Serrano S M, Santiago B, Juan I L, 2010. A Multiscalar drought index sensitive to global warming: the Standardized Precipitation Evapotranspiration Index SPEI. Journal of Climate, 23(7): 1696-1718. doi: http://dx. doi.org/10.1175/2009 JCLI2909.1

Wang C, Gower S T, Wang Y et al., 2001. The influence of fire on carbon distribution and net primary production of boreal Larix gmelinii forests in north-eastern China. Global Change Biology, 7(6): 719-730. doi: 10.1046/j.1354-1013.2001.00441.x

Westerling A L, Hidalgo H G, Cayan D R et al., 2006. Warming and earlier spring increase western US Forest wildfire activity. Science, 313(5789): 940-943. doi: 10.1126/science.1128834

Wilhite, D A, 2000. Drought as a Natural Hazard: Concepts and Definitions. Drought, a Global ssessment, Routledge Publishers, London, 3-18.

Wu Z W, He H S, Yang J et al., 2014. Relative effects of climatic and local factors on fire occurrence in boreal forest landscapes of northeastern China. Science of the Total Environment,
493(15): 472-480. doi: 10.1016/j.scitotenv.2014.06.011

Xiao J, Zhuang Q, Liang E et al., 2009. Twentieth-century droughts and their impacts on terrestrial carbon cycling in China. Earth Interactions, 13(10): 1-31. doi: 10.1175/2009EI275.1

Ye D Z, 1994. China's Global Change Research Advance (Part II). Seismological Press, Beijing. (in Chinese).

Yu D Y, Shao H B, Shi P J et al., 2009. How does the conversion of land cover to urban use affect net primary productivity? A case study in Shenzhen City, China. Agricultural and Forest Meteorology, 149(11): 2054-2060. doi: 10.1016/j.agrformet. 2009.07.012

Zhang B H, Zhang L, Guo H D et al., 2014. Drought impact on vegetation productivity in the Lower Mekong Basin. International Journal of Remote Sensing, 35(8): 2835-2856. doi: 10.1080/01431161.2014.890298

Zhang X, Goldberg M, Tarpley D et al., 2010. Drought-induced vegetation stress in southwestern North America. Environmental Research Letters, 5(2): 024008. doi: 10.1088/17489326/5/2/024008

Zhao M, Running S W, 2010. Drought-induced reduction in global terrestrial net primary production from 2000 through 2009. Science, 329(5994): 940-943. doi: 10.1126/science. 1192666

Zhou J, Zhang Z, Sun G et al., 2013. Response of ecosystem carbon fluxes to drought events in a poplar plantation in northern China. Forest Ecology and Management, 300: 33-44. doi: 10. 1016/j.foreco.2013.01.007

Zhou L M, Tucker C J, Kaufmann, R K et al., 2001. Variations in northern vegetation activity inferred from satellite data of vegetation index during 1981 to 1999. Journal of Geophysical Research-atmospheres, 106(D17): 20069-20083. doi: 10.1029/ 2000JD000115 